\title{
Longitudinal attentional engagement rescues mice from age-related cognitive declines and cognitive inflexibility
}

\author{
Louis D. Matzel, ${ }^{1}$ Kenneth R. Light, Christopher Wass, Danielle Colas-Zelin, \\ Alexander Denman-Brice, Adam C. Waddel, and Stefan Kolata \\ Department of Psychology, Program in Behavioral Neuroscience, Rutgers University, Piscataway, New Jersey 08854, USA
}

\begin{abstract}
Learning, attentional, and perseverative deficits are characteristic of cognitive aging. In this study, genetically diverse CD-1 mice underwent longitudinal training in a task asserted to tax working memory capacity and its dependence on selective attention. Beginning at 3 mo of age, animals were trained for $12 \mathrm{~d}$ to perform in a dual radial-arm maze task that required the mice to remember and operate on two sets of overlapping guidance (spatial) cues. As previously reported, this training resulted in an immediate (at $4 \mathrm{mo}$ of age) improvement in the animals' aggregate performance across a battery of five learning tasks. Subsequently, these animals received an additional $3 \mathrm{~d}$ of working memory training at 3-wk intervals for 15 mo (totaling 66 training sessions), and at 18 mo of age were assessed on a selective attention task, a second set of learning tasks, and variations of those tasks that required the animals to modify the previously learned response. Both attentional and learning abilities (on passive avoidance, active avoidance, and reinforced alternation tasks) were impaired in aged animals that had not received working memory training. Likewise, these aged animals exhibited consistent deficits when required to modify a previously instantiated learned response (in reinforced alternation, active avoidance, and spatial water maze). In contrast, these attentional, learning, and perseverative deficits were attenuated in aged animals that had undergone lifelong working memory exercise. These results suggest that general impairments of learning, attention, and cognitive flexibility may be mitigated by a cognitive exercise regimen that requires chronic attentional engagement.
\end{abstract}

Cognitive deficits are a defining feature of the phenotype of elderly humans (Riley and Riley Jr. 2000) as well as laboratory animals (Barnes and McNaughton 1985; Gallagher and Rapp 1997; Markowska and Savonenko 2002a; Gould and Feiro 2005; Matzel et al. 2008, 2009), and it has been estimated that as much as $25 \%-$ $50 \%$ of the age-related decline in cognitive/learning test performance is attributable to a perturbation of a latent influence on general cognitive abilities (Sternberg 1997; Sternberg and Kaufman 1998; Plomin 1999). Relatedly, the proportion of variance between individuals that is accounted for by general abilities increases across the life span, accounting for as much as $80 \%$ of the variance between elderly individuals as compared to only $\approx 40 \%$ among the rest of the population (Plomin and Spinath 2002).

It has been proposed that a decline in the processing capacity of working memory underlies much of the broad decline in cognitive function that accrues with age (Salthouse et al. 2003). This hypothesis is based on the widely held belief that components of the working memory system are recruited to accomplish (to varying degrees) any cognitive task, and thus are a critical determinant of general (cf. fluid) intelligence (Conway and Engle 1996). In young adults, it has been suggested that variations in working memory capacity and its related process, selective attention, may regulate general cognitive performance (Engle et al. 1999; Conway et al. 2003; Unsworth and Engle 2006), and similar processes have been proposed to regulate general learning abilities in genetically heterogeneous mice (Kolata et al. 2005, 2007; Light et al. 2010; for review, see Matzel and Kolata 2010). In fact, in mice, aging preferentially limits animals' working memory capacities (Matzel et al. 2008). This is potentially critical, as a dysregulation of "executive functions," which are heavily dependent

'Corresponding author.

E-mail matzel@rci.rutgers.edu; fax (732) 445-2263.

Article is online at http://www.learnmem.org/cgi/doi/10.1101//m.2034711. on the implementation of working memory and selective attention, is often asserted to broadly impact cognitive functions in aged human populations (Salthouse et al. 2003).

Related to the above-mentioned issues, it has recently been reported that working memory/selective attention training can have beneficial effects on performance across multiple cognitive domains in both humans (Jaeggi et al. 2008) and mice (Light et al. 2010). In a previous study, Light et al. (2010) provided young adult CD-1 mice with extensive working memory training. Prior to the working memory exercise (which in the human literature is often described as "attentional engagement" [Stine-Morrow 2007]), the animals were trained to navigate for food in two distinct eight-arm radial mazes. During two subsequent weeks of working memory training, the animals were required to perform in both mazes simultaneously, that is, choices in one maze alternated with choices in the other. As these two mazes shared a common set of spatial cues, accurate performance in each maze required that the animals maintain and segregate two sets of overlapping information, simultaneously using that information to independently navigate each maze. This training was believed to tax the processing components of working memory (i.e., capacity and selective attention) (Baddeley and Logie 1999; Baddeley 2003), and in fact, was found to promote an increase in selective attention in trained animals relative to both untrained animals and animals trained on a version of the task with a minimal selective attention demand. More importantly, trained animals exhibited an improvement in performance across a battery of five diverse learning tasks (that included fear conditioning, spatial water maze, odor discrimination, passive avoidance, and egocentric maze learning), suggesting that working memory exercise directly impacted general cognitive performance in young adult mice.

The above-mentioned results immediately raise two questions. First, would transient working memory training have 
lasting effects on general cognitive performance (Conway 2010)? Although Light et al. (2010) demonstrated that working memory training promoted an increase in general cognitive performance at least 2 mo after the completion of training, 2 mo represents only a fraction of the mouse's life span. A second obvious question raised by these results is whether chronic working memory training might slow (or mitigate) the onset of age-related cognitive declines. In the present paper we address this second question. Although it has previously been reported that "practice" on a specific task can maintain performance on that task across an animal's lifespan (Markowska and Savonenko 2002a; Vicens et al. 2003), it is unclear whether more general cognitive training (as would be instilled by a complex working memory/selective attention task) might have more broad protective effects across multiple learning and/or cognitive domains.

To address the above issue, at $\sim 3$ mo of age, mice were trained on an intensive working memory task for $2 \mathrm{wk}$, and were subsequently assessed for performance on a test of selective attention and five learning tasks. As noted previously, working memory training promoted an improvement in attentional and learning skills. Results obtained from these young animals were initially reported by Light et al. (2010). Upon completion of testing, a cohort of these animals began a 14-mo regimen of working memory training (or training on a control procedure with minimal working memory demands) during which $3 \mathrm{~d}$ of additional training was administered every $3 \mathrm{wk}$. At $\sim 18$ mo of age (roughly corresponding to 70 human years), animals underwent a series of tests to assess learning and selective attention. In addition to deficits in acquisition and retention, elderly humans exhibit difficulty in adapting previously learned responses to new situations (Span et al. 2004; Pesce et al. 2005). This reflects on the distinction between automatic (wherein fixed response patterns are effective in unchanging conditions) and controlled (wherein a learned concept is applied flexibly to changing conditions) forms of information processing (Poldrack and Packard 2003). Thus in the present paper, we also assessed the capacity of aged animals for task switching (or reversal learning), an ability that is presumed to be more heavily reliant on "executive functions" than is initial acquisition of a learned response (Salthouse 2005). In all cases, the performance of aged animals (those having undergone chronic working memory training and untrained control animals) was compared to the performance of a younger $(\sim 5$ mo old) cohort.

\section{Results}

\section{Task-specific learning and reversal performance}

First we will summarize the performance of young control, old control, and old animals that had undergone chronic working memory training on the four learning tasks administered here (i.e., step-down avoidance, reinforced alternation, shuttle avoidance, and spatial water maze). These tasks are presumed to impinge on different sensory, motor, motivational, and information processing systems.

\section{Step-down (passive) avoidance ( $n s=17[O L D / W M], 9[O L D / C]$, 12 [YOUNG/C])}

Upon stepping from a safe platform, animals were exposed to a presentation of a bright light and loud noise. The ratio of post-training-to-pretraining step latencies is illustrated in Figure 1A. Groups differed in their performance on the passive avoidance task, $F_{(2,35)}=7.28, P<0.05$. Planned comparisons indicated that YOUNG animals performed better than old animals that had not received working memory training $(\mathrm{OLD} / \mathrm{C}), F_{(1,35)}=9.66$,
$P<0.01$, but were statistically comparable to aged animals that had been administered chronic working memory training $(\mathrm{OLD} / \mathrm{WM}), F_{(1,35)}=0.18$, ns. Further, aged animals administered working memory training performed better than old control (OLD $/ \mathrm{C})$ animals, $F_{(1,35)}=14.91, P<0.01$. Finally, it should be noted that in this task (based on only a single training trial), aged animals that had not undergone working memory training (Group OLD/C) exhibited no post-training increase in step-down latency, suggesting that within these training parameters, old mice were incapable of learning this simple task.

\section{Reinforced alternation ( $n s=17[\mathrm{OLD} / \mathrm{WM}], 8[\mathrm{OLD} / \mathrm{C}], 12[\mathrm{YOUNG} / \mathrm{C}]$ )}

Animals were trained to alternate between arms in a T-maze to obtain reinforcement. To assess animals' acquisition rates, a criterion of four consecutive correct alternations was chosen, and the trial at which this run of correct responses began was compared across groups (see Fig. 1B1) revealing a significant difference, $F_{(2,34)}=14.11, P<0.001$. Planned comparisons indicated that YOUNG/C animals performed better than old animals that had not received working memory training $(\mathrm{OLD} / \mathrm{C}), F_{(1,34)}=18.96$, $P<0.001$, but were statistically comparable to aged animals that had been administered chronic working memory training $(\mathrm{OLD} / \mathrm{WM}), F_{(1,34)}=0.50$, ns. Further, aged animals administered working memory training performed better than old control $(\mathrm{OLD} / \mathrm{C})$ animals, $F_{(1,34)}=29.46, P<0.001$.

Animals received a total of 24 training trials, and thus by the end of training had all received training that exceeded criterion by an average of $\approx 16$ training trials. At this point, conditions were reversed such that animals were required to return to the arm previously reinforced in order to obtain reinforcement (i.e., the training conditions were switched from win-shift to win-stay) (Fig. 1B2). During this phase of training, one animal was lost from the OLD/WM group. Again, a comparison of trials-tocriterion revealed a difference between groups, $F_{(2,33)}=21.99$. $P<0.001$. Planned comparisons indicated that YOUNG/C animals performed better than old animals that had not received working memory training $(\mathrm{OLD} / \mathrm{C}), F_{(1,33)}=43.59, P<0.001$, but were statistically comparable to aged animals that had been administered chronic working memory training (OLD/WM), $F_{(1,33)}=3.23, P<0.10$, although in this instance, young animals did exhibit a tendency toward better performance. However, aged animals administered working memory training performed better than old control $(\mathrm{OLD} / \mathrm{C})$ animals, $F_{(1,33)}=22.05, P<0.001$.

Shuttle (active) avoidance (ns = 13 [OLD/WM], 7 [OLD/C], $10[$ YOUNG/C]) Animals were trained to associate the onset of a light and the opening of a door with the subsequent (10 sec later) onset of shock. The animals could avoid shock by moving through the door to the opposite side of the box (and could always escape shock after its onset). To assess animals' acquisition rates, a criterion of four consecutive successful avoidance responses was chosen, and the trial at which this run of correct responses began was compared across groups (see Fig. 1C1) revealing a significant difference, $F_{(2,34)}=14.11, P<0.001$. Planned comparisons indicated that YOUNG animals performed better than old animals that had not received working memory training (OLD/C), $F_{(1,34)}=18.96, P<0.001$, but were statistically comparable to aged animals that had been administered chronic working memory training $(\mathrm{OLD} / \mathrm{WM}), F_{(1,34)}=0.50$, ns. Further, aged animals administered working memory training performed better than old control $(\mathrm{OLD} / \mathrm{C})$ animals, $F_{(1,34)}=29.46, P<0.001$.

Animals received a total of 24 training trials, and thus by the end of training had all received training that exceeded criterion by an average of $\approx 12$ training trials. At this point, animals received 

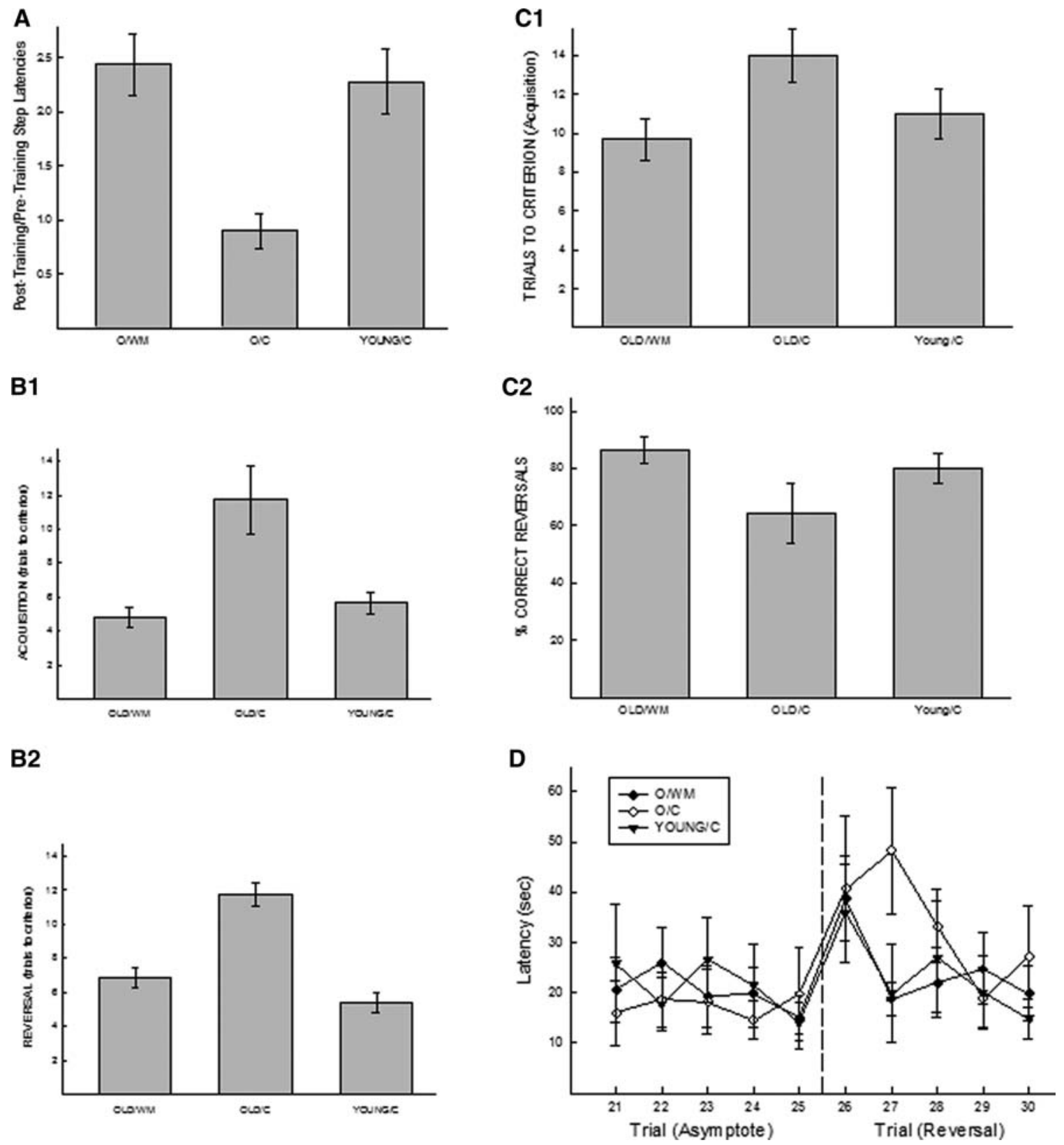

Figure 1. (A) Step-down (passive) avoidance. Old (18 mo) mice received working memory training (OLD/WM) or a control procedure (OLD/C) across their lifespan. Young $(6 \mathrm{mo})$ animals (Group YOUNG/C) received a treatment similar to Group OLD/C for 3 mo. All animals were then assessed for learning on a passive avoidance task. Illustrated are group means \pm standard errors. (B) Reinforced alternation and reversal. Old (18 mo) mice received working memory training (OLD/WM) or a control procedure (OLD/C) across their lifespan. Young $(6 \mathrm{mo})$ animals (Group YOUNG/C) received a treatment similar to Group OLD/C for 3 mo. (B1) All animals were then assessed for learning on a reinforced alternation task. (B2) Subsequently, conditions were changed such that reinforcement was consistently delivered in only one of the two opposing arms. Illustrated is the average number of trials to reach a preestablished criterion of four consecutive correct responses ( \pm standard error). (C) Shuttle avoidance and reversal. Old (18 mo) mice received working memory training (OLD/WM) or a control procedure (OLD/C) across their lifespan. Young (6 mo) animals (Group YOUNG/C) received a treatment similar to Group OLD/C for 3 mo. (C1) All animals were then assessed for learning to avoid shock in a one-way shuttle avoidance task. Illustrated is the average number of trials to reach a pre-established criterion of four consecutive avoidance responses ( \pm standard error). (C2) After all animals had attained super-asymptotic levels of performance, conditions were changed such that shock could be avoided by remaining in the start compartment (rather than shuttling to the opposite side of the box). Illustrated is the percent of trials (out of four after one reversal training trial) in which animals made a successful avoidance response after conditions were reversed. (D) Spatial water maze reversal. Old (18 mo) mice received working memory training (OLD/WM) or a control procedure (OLD/C) across their lifespan. Young $(6 \mathrm{mo})$ animals (Group YOUNG/C) received a treatment similar to Group $\mathrm{OLD} / \mathrm{C}$ for $3 \mathrm{mo}$. All animals were then trained to locate a hidden platform in a spatial water maze. Illustrated is the average ( \pm standard error of the mean) latency to locate the hidden platform during the final acquisition trials and then after the hidden platform was moved to a new location. 
five reversal trials wherein shock could be avoided by remaining on the side of the box that contained the light CS. During this phase of training, one animal was lost from the O/WM group. On the first of these trials (and consistent with previous shuttle training), all animals moved to the side opposite the light CS (and thus all animals received shock). Of interest was the percent of the remaining four trials in which the animals successfully avoided shock. Again, comparison of the percent of trials with a successful avoidance response indicated a difference between the three groups, $F_{(2,33)}=21.99, P<0.001$ (Fig. 1C2). Planned comparisons indicated that YOUNG/C animals performed better than old animals that had not received working memory training $(\mathrm{OLD} / \mathrm{C}), F_{(1,33)}=43.59, P<0.001$, but were statistically comparable to aged animals that had been administered chronic working memory training $(\mathrm{OLD} / \mathrm{WM}), F_{(1,33)}=3.23, P<0.10$, although in this instance, young animals did exhibit a tendency toward better performance. However, aged animals administered working memory training performed better than old control (OLD/C) animals, $F_{(1,33)}=22.05, P<0.001$.

\section{Spatial water maze (ns = $16[O L D / W M], 8[O L D / C], 12[Y O U N G / C]$ )}

Animals were trained to locate a hidden platform submerged below the surface in a tank of opaque water. Figure 1D (left panel) illustrates the latency to locate the hidden platform recorded across the last five of 25 training trials. Only the last five trials of training are illustrated as no differences between groups were observed in the acquisition phase of training, and in fact, all animals performed at high degrees of efficiency even on the initial training trials. This likely reflects the fact that all animals had previously undergone water maze training, although during that training, the maze was visually distinct from the present maze (black water and surround instead of the present white), the previous maze utilized a different set of visual cues, and the escape platform was located in a different quadrant of the maze. Despite the novelty of the present version of the task, apparently this prior training conferred a substantial advantage to the animals when learning this new version of the maze. In this regard, it is notable that "pretraining" or adaptation to the conditions of a water maze often protects animals from manipulations that are otherwise presumed to impact animals' capacities for spatial learning (Cain et al. 1996). Consequently, acquisition data in the present maze provides no useful comparison between the groups, although it is evident from Figure 1D that aged animals achieved a level of performance that was comparable to young animals (indicative of no functional deficit in the motor requirements of swimming or the perception of visual cues). In contrast, when the hidden platform was moved to a new location on the 26th trial, performance across groups was differentially affected. An ANOVA of the data obtained on the last five training trials and the five reversal trials indicated a significant effect of trials, $F_{(2,9)}=2.13, P<$ 0.03. Planned comparisons found no differences between groups on any of the five trials prior to reversal training ( $F \leq 1.02$, ns), indicating that the groups reached comparable levels of performance by the end of training. Likewise, the groups did not differ on the first reversal trial (Trial 26), indicating comparable degrees of disruption in performance $(F \leq 0.86$, ns) when the location of the escape platform was shifted. However, old animals that had not undergone working memory training $(\mathrm{OLD} / \mathrm{C})$ were slow to recover from this disruption (i.e., on the second reversal trial; Trial 27), differing from young animals, $F_{(1,18)}=5.93, P<0.05$, and old animals that had undergone working memory training $(\mathrm{OLD} / \mathrm{WM}), \quad F_{(1,18)}=9.08, \quad P<0.01$. Groups $\mathrm{OLD} / \mathrm{WM}$ and YOUNG/C did not differ on this $(F=0.11, \mathrm{~ns})$. Comparable levels of performance were observed on trials 28-30 (the last three trials of reversal training), $F \leq 0.86$, ns.

\section{Selective attention}

Upon completion of all learning tests, animals were assessed for performance in a test of selective attention. Following overtraining on odor and visual discriminations (in separate, distinct boxes), the animals performed a complex discrimination task to assess attentional abilities. In these trials, the odor cues from the odor discrimination box were introduced into the visual discrimination box and acted as salient task-relevant distracters (in a manner analogous to the human Stroop test). Animals received four such trials, and the total number of errors was once again recorded. Of interest was the number of errors made in the visual discrimination with the odor cues acting as distracters relative to the errors committed in the visual discrimination when the odor cues were absent. Groups did not differ in errors committed in the last four trials of visual discrimination prior to the introduction of the odor distracters (average number of errors per trial = $0.1,0.08$, and 0.05 , Groups OLD/WM $[n=11]$, OLD/C $[n=6]$, and YOUNG/C $[n=9]$, respectively), $F_{(2,23)}=0.91$, ns. However, when odor distracters were added to the visual discrimination, errors increased (Fig. 2), and did so differentially across groups, $F_{(2,23)}=3.48, \quad P<0.05$. Planned comparisons indicated that Group OLD/WM performed better in this test of selective attention than did Group OLD $/ \mathrm{C}, F_{(1,23)}=7.43, P<0.05$. The nominal deficit in Group OLD/C relative to Group YOUNG/C did not reach statistical significance, $F_{(1,23)}=1.84$, ns.

\section{General cognitive performance}

Animals exhibited a wide range of variability in performance across tasks, although some individuals consistently performed better or worse than the median performance on all tasks, a result that is consistent with prior work (Matzel et al. 2003, 2006; Kolata et al. 2008) and indicative of a conserved influence on performance across tasks. To quantify these observations, first a principal component analysis was conducted on the acquisition data, the reversal data, and selective attention data from the subset of mice that contributed data to all of these tasks (ns $=11,6$, and 9, Groups OLD/WM, OLD/C, and YOUNG/C, respectively). To that end, a correlation matrix (Table 1) was constructed and it

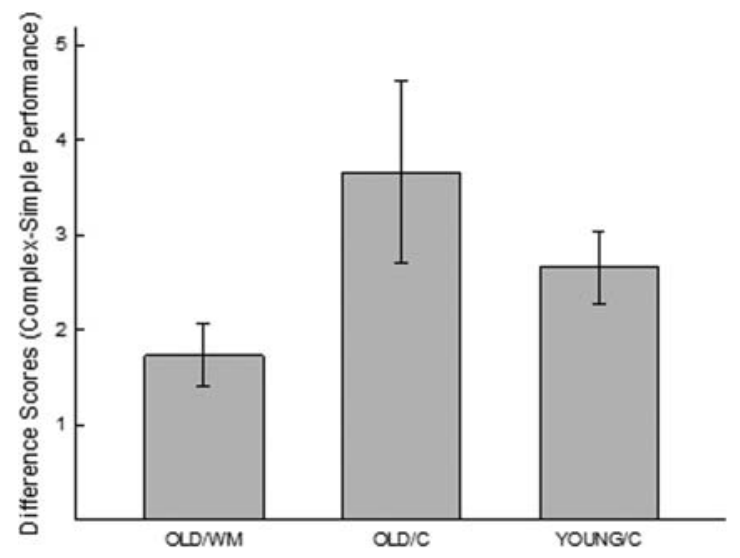

Figure 2. Selective attention. Animals performed odor discrimination and visual discrimination in each of two distinct contexts. After attaining superasymptotic (and near errorless) performance on each of these tasks, the odor and visual cues were simultaneously presented in the context that signaled the visual discrimination. This constituted a mouse analog of the human Stroop test, where task-relevant distracters must be ignored in order for the animal to perform efficiently. The errors across four test trials (relative to errors in the simple discrimination) are plotted as a function of group. Lifelong working memory training facilitated selective attention in aged animals. 
Table 1. Matrix of correlations of performance in tests of acquisition, reversal, and selective attention

\begin{tabular}{|c|c|c|c|c|c|c|c|}
\hline & $\begin{array}{l}\text { Selective } \\
\text { attention }\end{array}$ & $\begin{array}{c}\text { Passive } \\
\text { avoidance }\end{array}$ & $\begin{array}{l}\text { Reinforced } \\
\text { alternation } \\
\text { (acquistion) }\end{array}$ & $\begin{array}{l}\text { Reinforced } \\
\text { avoidance } \\
\text { (reversal) }\end{array}$ & $\begin{array}{c}\text { Shuttle avoidance } \\
\text { (acquisition) }\end{array}$ & $\begin{array}{c}\text { Shuttle } \\
\text { avoidance } \\
\text { (reversal) }\end{array}$ & $\begin{array}{l}\text { Water maze } \\
\text { (reversal) }\end{array}$ \\
\hline SA & & 0.42 & 0.17 & 0.26 & 0.35 & 0.25 & 0.19 \\
\hline PA & 0.42 & & 0.58 & 0.29 & 0.02 & 0.35 & 0.13 \\
\hline RA (Acq) & 0.17 & 0.58 & & 0.38 & 0.04 & 0.55 & 0.32 \\
\hline RA_(Rev) & 0.26 & 0.29 & 0.38 & & 0.10 & 0.25 & 0.30 \\
\hline SHUT_(Ácq) & 0.35 & 0.02 & 0.04 & 0.10 & & 0.02 & 0.11 \\
\hline SHUT_(Rev) & 0.25 & 0.35 & 0.55 & 0.25 & 0.02 & & 0.09 \\
\hline WM_(Rev) & 0.19 & 0.13 & 0.32 & 0.30 & 0.11 & 0.09 & \\
\hline
\end{tabular}

was observed that all correlations were in a positive direction, indicative of a common source of variance across all cognitive tests. (It is noted that for this analysis, with one exception, the same data that contributed to the between-group analyses contributed here. In the one exception, for the water maze, only the second trial of reversal training [where relevant group differences were expected and observed] contributed to the principal component analysis.) Principal component analysis extracted a principal factor that accounted for $37 \%$ of the variance across tasks (Table 2). Performance indicative of all cognitive tests loaded in a consistent direction on this factor, and all variables exhibited moderate-to-strong loading weights. From this analysis, a single factor score was derived for each animal. A factor score is analogous to each animal's average $Z$-score for the six tasks, with each $Z$-score weighted by the extent to which the corresponding task contributed to the principal factor. Factor scores served to rank animals on the variable captured by the principal factor, where positive values indicate overall performance that was better than the group mean, and negative values indicate performance that was worse than the group mean. Factor scores were separated by group (OLD/WM, OLD/C, and Young/C) (see Fig. 3), and ANOVA indicated a significant difference between groups, $F_{(2,23)}=50.68, P<0.0001$. Planned comparisons indicated that the aggregate performance of old animals that had not undergone working memory training $(\mathrm{OLD} / \mathrm{C})$ was worse than that exhibited by both old animals that had undergone working memory training $(\mathrm{OLD} / \mathrm{WM}), F_{(1,23)}=95.9, P<0.0001$, and from YOUNG $/ \mathrm{C}$ animals, $F_{(1,23)}=77.64, P<0.0001$. Old animals that had undergone working memory training did not differ from YOUNG animals, $F_{(1,23)}=0.20$, ns.

\section{Noncognitive influences on cognitive performance}

Owing to the rapid attrition (owing to death or intolerance of food deprivation) of aged subjects that began near the completion of this experiment, an extensive set of sensory motor tests, like we have previously administered to aged mice (Matzel et al. 2008), were not administered here. However, several measures of motor function and exploration could be derived from the tests described previously.

Swimming Speed $(\mathrm{ns}=11 \quad[\mathrm{OLD} / \mathrm{WM}], 8 \quad[\mathrm{OLD} / \mathrm{C}], 11$ [YOUNG/C]). Animals' performance in the water maze allowed us to estimate swimming speed from the period of uninterrupted swimming during the animals' first exposure to the maze. Owing to a video recording failure (which prohibited our reporting of path lengths above), all of the animals that contributed latencies were not available for the analysis of swimming speed. Of the animals that provided data, ANOVA revealed no overall difference between groups, $F_{(2,27)}=0.51$, ns. However, young animals did exhibit a tendency to faster swimming speeds (mean $=6.22 \mathrm{~cm} /$ $\sec \pm 1.43 \mathrm{SEM}$ ) compared to old animals that had undergone working memory training $(4.18 \mathrm{~cm} / \mathrm{sec} \pm 1.32 \mathrm{SEM})$ or old control animals $(4.46 \mathrm{~cm} / \mathrm{sec} \pm 0.90$ SEM). Planned comparisons found no significant differences between groups.

\section{Running speed (ns = $15[\mathrm{OLD} / \mathrm{WM}], 9[\mathrm{OLD} / \mathrm{C}], 11[\mathrm{YOUNG} / \mathrm{C}]$ )}

Animals were trained to run through a $32 \mathrm{~cm}$ alley to obtain a food reward. After animals were performing at asymptotic levels (during which they typically run without pausing) the time to complete the run (from its initiation to completion) was recorded and the average of three trials was used to compute running speed. ANOVA revealed no difference between groups, $F_{(2,32)}=$ 0.11 , ns, and likewise, planned comparisons did not reveal any differences between groups (means $=36.45 \pm 1.24,36.69 \pm 2.13$, and $35.62 \pm 1.95 \mathrm{~cm} / \mathrm{sec}$ for Groups OLD $/ \mathrm{WM}$, OLD/C, and YOUNG/C, respectively).

\section{Exploration (ns = $17[\mathrm{OLD} / \mathrm{WM}], 9[\mathrm{OLD} / \mathrm{C}], 11[\mathrm{YOUNG} / \mathrm{C}]$ )}

No explicit measure of exploration was obtained throughout this experiment. However, the latency to reach the goal box in a Lashley maze prior to receiving any food in that maze (i.e., on the first training trial) is a least in part indicative of an animal's propensity for exploration, as animals that reach the goal box sooner (prior to receiving any food there) are judged to be more prone to enter novel environments. ANOVA revealed no differences in the latencies between groups, $F_{(2,34)}=1.22$, ns. However, Group OLD/WM did exhibit a tendency to shorter latencies than either Groups OLD/C and YOUNG/C (means $=53.7 \pm$ $7.75,64.9 \pm 17.3$, and $77.36 \pm 12.64 \mathrm{sec}$ for Groups OLD/WM, $\mathrm{OLD} / \mathrm{C}$, and YOUNG/C, respectively).

\section{Body weights (ns $=15[O L D / W M], 9[O L D / C], 11[Y O U N G / C]$ ).}

Body weights were monitored across the duration of this experiment. Relevant to the present purpose, body weights were compared across groups at the start of the cognitive testing ( $\sim 18 \mathrm{mo}$ [OLD] or $5 \mathrm{mo}$ [YOUNG] of age). ANOVA indicated a significant difference between groups, $F_{(2,32)}=4.69, P<0.02$. Group $\mathrm{O} / \mathrm{WM}($ mean $=46.8 \pm 0.80)$ and Group OLD $/ \mathrm{C}($ mean $=46.6 \pm$

Table 2. Unrotated principal component analysis of acquisition, reversal, and selective attention performance

\begin{tabular}{lcr}
\hline & Factor $\mathbf{1}$ & Factor 2 \\
\hline Selective attention & 0.58 & -0.53 \\
Passive avoidance & 0.73 & 0.16 \\
Reinforced alt. (acquisition) & 0.61 & 0.34 \\
Reinforced alt. (reversal) & 0.79 & -0.03 \\
Shuttle avoid. (acquisition) & 0.23 & -0.81 \\
Shuttle avoidance (reversal) & 0.65 & 0.31 \\
Water maze (reversal) & 0.45 & -0.18 \\
$\quad$ Eigenvalue & 2.59 & 1.23 \\
Proportion of variance & 0.37 & 0.17 \\
\hline
\end{tabular}




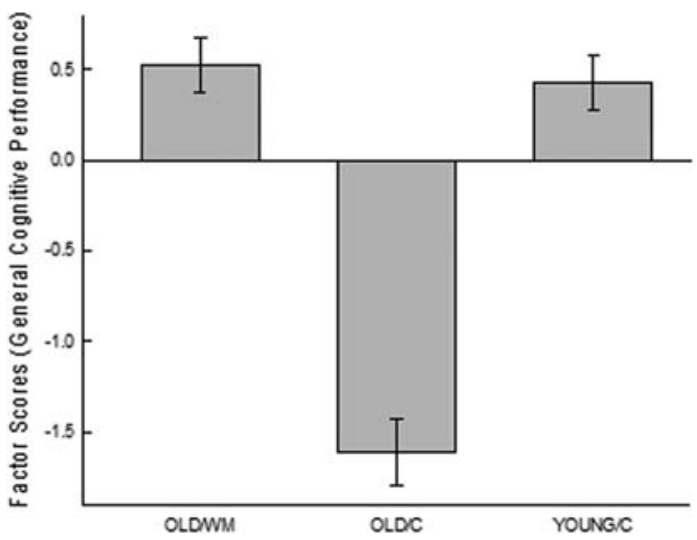

Figure 3. General cognitive performance. Old $(18 \mathrm{mo})$ mice received working memory training (OLD/WM) or a control procedure $(\mathrm{OLD} / \mathrm{C})$ across their lifespan. Young $(6 \mathrm{mo})$ animals (Group YOUNG/C) received a treatment similar to Group OLD/C for 3 mo. All animals were then assessed for acquisition on three learning tasks (passive avoidance, shuttle avoidance, and reinforced alternation), for reversal learning in three tasks (shuttle avoidance, reinforced alternation, and spatial water maze), and for selective attention. Performance measures on each of these tasks were then subjected to a principal components analysis (see Table 2). From this analysis, a factor score was derived for each animal that represented its general learning performance. Average factor scores for each group are plotted; brackets indicate standard errors. Lifelong working memory training (OLD/WM) attenuated the general cognitive decline that was observed in aged animals that had undergone a control procedure that made minimal demands on working memory $(\mathrm{OLD} / \mathrm{C})$.

2.30) did not differ, $F_{(1,32)}=0.01$, ns. However, Groups $\mathrm{O} / \mathrm{WM}$ and OLD $/ \mathrm{C}$ each differed from Group YOUNG/C (mean $=42.07 \pm$ $0.94), \quad F_{(1,32)} \geq 6.05, \quad P s<0.02$. These results indicate that although aging was associated with weight gain, explicit working memory training had no impact on this weight gain beyond that which may have been promoted by the control training procedure. Thus, the impact of working memory training on cognitive performance is not likely attributable to a simple exercise effect.

\section{The relationship of noncognitive variables to general cognitive performance}

To further characterize the relationship of variations in noncognitive performance to general cognitive performance, a principal component analysis was conducted on the acquisition, reversal, and selective attention data, as well as noncognitive performance data from the subset of mice that contributed to all of these tasks (ns $=11,6$, and 9, Groups OLD/WM, OLD/C, and YOUNG/C, respectively). The results of this analysis are provided in Table 3. Looking at Factor 1, again, all cognitive variables loaded consistently in a moderate-to-heavy manner. Noncognitive variables loaded moderately-to-weakly in an inconsistent manner. Of note, swimming speed loaded most weakly (0.09), further suggesting, like the other analyses described previously, that swimming speed could not account for differences between individuals (and hence groups) in the water maze reversal performance. Of the noncognitive variables, running speed loaded most heavily $(-0.45)$, but as none of the cognitive performance indices were based on running speed, this moderate degree of loading is unlikely to have impacted any of the cognitive performance measures (and instead may be a covariate of body weight). It should also be noted that the direction in which running speed loaded on this factor suggests (albeit weakly if at all) that slower running speed was associated with better cognitive performance, further indicating that running speed is unlikely to account for the observed differences in cognitive performance between young and old animals.

Noncognitive variables loaded more consistently and in a moderate-to-heavy manner on Factor 2 of this principal component analysis. In contrast, cognitive variables loaded inconsistently on this factor. Although the amount of variability in performance accounted for by this factor is quite low, the most parsimonious explanation for the pattern of loadings across Factors 1 and 2 is that the four noncognitive variables considered here are not consistently related to the overall pattern of cognitive performance expressed by these animals.

\section{Discussion}

Relative to young animals, aged animals that had not undergone working memory training exhibited marked deficits in the acquisition of learned responses that represent different learning processes (i.e., "domains"), sensory, motor, and motivational requirements, and presumably, neuroanatomical dependence. Deficits were observed in reinforced alternation, passive avoidance, and active avoidance. In two of these tasks (reinforced alternation and active avoidance), as well as a third task (spatial water maze), old animals that had not undergone working memory training exhibited deficits when conditions were changed so as to demand a new behavioral response to obtain the same desired outcome, i.e., aged animals exhibited deficits in "cognitive flexibility," a capacity that is representative of what is characteristically described as an "executive function" (Salthouse 2005). Consistent with the nature of these deficits, the aged animals exhibited impaired performance on a specific test of selective attention, a skill that is critical to the proper control of working memory (Baddeley and Logie 1999; Conway et al. 2003; Matzel and Kolata 2010). Thus, not only were aged animals impaired in the acquisition of new learning, they exhibited broad deficits in functions related to cognitive control and flexibility. In combination with previous work of our own (Matzel et al. 2008, 2009) and others (e.g., Barnes 1979; Barnes and McNaughton 1985; Markowska and Savonenko 2002b; Gould and Feiro 2005), these results further indicated that aging impacts performance across a wide range of basic learning domains, as well as higher cognitive functions.

Studies of cognitive aging are often subject to interpretative difficulties owing to the potential impact of noncognitive performance variables on measures of cognition or learning. In a prior analysis similar to the one reported here (Matzel et al. 2008), a wide range of sensory, motor, and emotional variables

Table 3. Unrotated principal component analysis of acquisition, reversal, selective attention, and noncognitive performance variables

\begin{tabular}{lcr}
\hline & Factor 1 & Factor 2 \\
\hline Selective attention & 0.61 & 0.55 \\
Passive avoidance & 0.72 & -0.15 \\
Reinforced alt. (acquisition) & 0.68 & -0.40 \\
Reinforced alt. (reversal) & 0.54 & -0.30 \\
Shuttle avoid. (acquisition) & 0.28 & 0.54 \\
Shuttle avoidance (reversal) & 0.74 & -0.07 \\
Water maze (reversal) & 0.34 & -0.27 \\
Body weight & 0.34 & 0.27 \\
Running speed & -0.45 & 0.34 \\
Swimming speed & -0.09 & 0.30 \\
Exploration & 0.37 & 0.82 \\
Eigenvalue & 2.88 & 1.95 \\
Proportion of variance & 0.26 & 0.18 \\
\hline
\end{tabular}


were assessed in combination with multiple measures of cognitive ability. While aged animals were clearly distinguished from their young counterparts on many noncognitive domains, factor analyses indicated that those variations in noncognitive performance (with the exception of body weight) accounted for little of the variance in performance across the battery of cognitive tests. Although only a small number of noncognitive variables were assessed in the present study (i.e., swim speed, running speed, exploratory tendencies, and body weight), a similar conclusion can be drawn from these data. Although a tendency was observed for slower swim speeds in old relative to young animals, these performance measures had no consistent explanatory value in describing cognitive performance although they did load consistently on a separate noncognitive factor. It is also worth noting that both groups of aged animals were heavier than their young counterparts. Importantly however, old animals that had undergone working memory training did not differ in body weight from old animals that underwent control training (i.e., training with no explicit attentional or working memory demands). This indicates that working memory training did not impact cognitive performance through any effect on fitness (at least fitness related to body weight). In total, these results indicate that old animals are impaired in several measures of noncognitive performance, but that these noncognitive variations are unlikely to explain the differences in cognitive performance between young and old animals or old animals that had undergone working memory or control training procedures.

True longitudinal studies of cognitive aging with human subjects are quite rare or are circumscribed in their duration. Laboratory animals provide a practical means to overcome the difficulties associated with longitudinal studies of humans, but even so, are uncommon relative to cross-sectional analyses. Attempts to assess the effects of behavioral or environmental manipulations on the development of age-related cognitive declines have been relatively infrequent, although several examples should be noted. For instance, it has been reported that repetitive lifelong exposure from a young age promotes a preservation of object recognition memory (as well as reduced anxiety and enhanced hippocampal neurogenesis) in aged mice (Leal-Galicia et al. 2008). Most relevant to the present study, it has been reported that in both rats (Markowska and Savonenko 2002a) and mice (Vicens et al. 2003) early training in a spatial water maze protects animals from the declines in performance in these mazes that typically accompany aging. However, it is not clear from these studies if early exposure to the water maze would promote performance in other cognitive tasks or domains, and likewise, the underlying process that is being impacted by water maze training. In the present experiments, it was determined that a form of lifelong cognitive exercise that specifically taxed working memory capacity and/or selective attention preserved performance in both a novel selective attention task (modeled after the human Stroop test), as well as three distinct learning tasks (passive avoidance, active avoidance, and reinforced alternation). Further, this working memory/selective attention exercise allowed animals to maintain a high level of cognitive flexibility, such that when task demands were altered (or "reversed") animals having undergone this exercise rapidly (and successfully) adapted to the new conditions. (It is worth noting that prior to any test of reversal, all animals were trained to a comparable high level of competency on the initial learning task. This was a critical manipulation, because reversal performance would be likely to vary as a function of initial learning.)

Much speculation has arisen regarding the assertion that aging differentially impacts what is commonly described as "executive function" (Salthouse and Ferrer-Caja 2003). Executive function is a theorized cognitive system that is said to control and manage other cognitive processes. As such, working memory and selective attention are believed to be central components of the executive system. In prior research, we have demonstrated that aspects of working memory (including both working memory capacity and span) are differentially impacted by aging (Matzel et al. 2008). Further, Young et al. (2010) demonstrated that although young and old mice exhibit similar learning rates on an attentional-set-shifting task, aged mice were differentially impaired in a test of extra dimensional shifting, a process that is known to be mediated by the frontal cortex and is representative of executive abilities. Like set shifting, reversal learning is thought to depend heavily on selective attention (and thus executive control). However, in the present data, reversal performance did not appear to be differentially impacted (relative to simple acquisition) by aging. In only one instance (in the spatial water maze) were we sensitive to an effect of aging on reversal that was not seen in initial acquisition. Nevertheless, inspection of Table 2 does indicate higher loadings of reversal performance than acquisition performance on the same task. Thus, the present data does provide marginal evidence for a differential effect of aging on behavioral tasks that are more heavily dependent on executive-like functions.

In prior studies it has been observed that aged animals exhibit considerably more variability in cognitive performance than do their young counterparts (Lund et al. 2004; Matzel et al. 2008), so much so that aged animals could be segregated into those with age-related impairments and those that had been spared entirely. Only a trend toward such increased variability was observed here. In a measure of aggregate performance across the battery of cognitive tests (based on a comparison of factor scores), the variability in aged control animals did not differ from aged animals that had undergone working memory training or their young counterparts (see Fig. 3). This homogeneity of variance in aggregate performance (among genetically heterogeneous mice) was observed despite the slight increase in variability of aged animals in most of the individual cognitive tasks. Of particular note was the performance of aged control animals on the explicit test of selective attention, where the variability in performance of these animals was greater than twice that observed in young animals or aged animals that had received working memory training. As it has been our contention that selective attention is likely to impact performance on the other cognitive tests reported here (Yarkoni et al. 2005; Matzel et al. 2008; Matzel and Kolata 2010), it is unclear why this increased variability in selective attention did not translate into greater variability in the measure of general cognitive performance. A better understanding of this seeming paradox might be obtained through independent factor analyses of the performance of the individual groups tested here. Unfortunately, the group sizes that existed at the completion of this study were sufficiently small (owing to attrition) to prohibit such individual analyses.

Based on a combined principal component analysis of the performance on all of the cognitive tasks (including learning, reversal, and selective attention tests) of young and old animals, each animal in this study was assigned a factor score (analogous to an average $Z$-score of an animal's performance across all tasks), and this score served to characterize the general learning abilities of each animal relative to the others in this sample. A comparison of the factor scores of young (YOUNG/C) and old (OLD/C) animals indicated significantly impaired general cognitive performance in aged animals. However, aged animals that had been provided with lifelong working memory/selective attention training (OLD/WM) exhibited general cognitive abilities that were indistinguishable from their young counterparts. Thus, consistent with recent theory (e.g., Stine-Morrow 2007), cognitive aging is demonstrated here to be the expression of a combination 
of both an innate genetic predisposition, as well as life experience, and contrasts with suggestions that cognitive decline is an immutable consequence of the aging process (Molden and Dweck 2006).

The data reported here suggest that the implementation, through repeated exercise, of attentional engagement can mitigate the characteristic declines in cognitive abilities that typically accompany aging (also see Kramer et al. 2004; Stine-Morrow et al. 2006). It is worth noting that subregions of the prefrontal cortex (PFC) may play a critical role in the mediation of general cognitive performance through their regulation of attentional control and/ or working memory capacity (Sawaguchi and Goldman-Rakic 1991; Durstewitz et al. 2000; Thurley et al. 2008; Kolata et al. 2010; for review, see Matzel and Kolata 2010). In fact, Kolata et al. (2010) have reported that the expression levels of a cluster of dopamine D1-related genes in the prefrontal cortex predict animals' general cognitive performances. It is tempting to speculate that working training might impact this same dopaminergic cluster (or its functional constituents), and thus might modulate cognitive abilities in a manner similar to that with which it modulates innate cognitive abilities. Although the present work does not allow us to evaluate this hypothesis, it has been reported that dopaminergic transmission is reduced in the PFC of aged rats, and further, that direct stimulation of the PFC with dopamine D1 receptor agonists promotes an improvement in working memory performance in those animals (Mizoguchi et al. 2009).

\section{Materials and Methods}

\section{Subjects}

Three groups of male CD-1 mice were used in this experiment. Two groups of animals arrived in our laboratory at $\sim 45 \mathrm{~d}$ of age. The third group arrived (also at $\sim 45 \mathrm{~d}$ of age) $\sim 13$ mo after the initial two groups, such that at the initiation of critical behavioral testing, two groups were $\sim 18$ mo of age ("OLD"), and one group was $\sim 5$ mo of age ("YOUNG" $n=11$ ). During their time in our laboratory, these animals served only in this experiment, i.e., did not act as breeders or in any other capacity. Two groups of old animals received either chronic working memory training ("OLD/WM", $n=18$ ) or a control treatment ("OLD/C", $n=9$ ). (The unequal group sizes reflect the fact that the animals used here began as a cohort in a larger study [Light et al. 2010] that was previously reported. Part of this cohort was used for purposes not originally intended, leaving the group sizes as they presently stand.) Throughout the course of working memory training, one animal in each of the OLD conditions died, resulting in final ns of 17 and 8 . At the start of behavioral testing, young mice ranged from 26.4 to $36.4 \mathrm{~g}$, aged control mice from 31.1 to $42.9 \mathrm{~g}$, and aged working memory-trained mice from 32.9 to $42.8 \mathrm{~g}$.

All animals were housed individually in clear shoebox cages in a temperature and humidity controlled colony room and were maintained on a 12-h light/dark cycle. In order to minimize defensive behaviors (which can impede goal-directed behaviors) that often occur in response to handling, from the time of arrival in our laboratory until the start of the experiment, all animals were handled by an experimenter (removed from their home cages and held by an experimenter) for $60 \mathrm{sec} / \mathrm{d}, 5 \mathrm{~d} / \mathrm{wk}$. Similar handling was administered in any weeks in which no experimental manipulations were scheduled. Critical behavioral testing required $\sim 10 \mathrm{wk}$ to complete, such that testing of young and aged mice was concluded at $\sim 7.0$ and 20.5 mo of age, respectively.

\section{Food deprivation}

For the cognitive tasks that required food deprivation, ad libitum food was removed from the animals' home cages at the end of the light cycle $\sim 40 \mathrm{~h}$ prior to the start of training (and thus encompassing the "rest" day between successive tasks). During the deprivation period, animals were provided with food in their home cages for $90 \mathrm{~min} / \mathrm{d}$ during the last $2 \mathrm{~h}$ of the light cycle, and thus were $\sim 16 \mathrm{~h}$ food-deprived at the time of training or testing. This deprivation schedule was deemed "mild" (animals typically lost $<5 \%$ of their free-feeding body weight during this period), but was sufficient to maintain stable performance on these tasks.

\section{Behavioral training and testing}

Animals that would ultimately be tested at $18 \mathrm{mo}$ of age were assigned to one of two groups at $70 \mathrm{~d}$ of age. Animals were randomly assigned to these groups, with the exception of balancing for animal weights and exploratory tendencies based on a pretest in an elevated plus maze. (Exploratory behavior is strongly predictive of general cognitive abilities [Matzel et al. 2003, 2006; Grossman et al. 2007]; and thus served to balance the groups prior to training.) Working memory training was given to one of these two groups, whereas the other received training with similar sensory and motor demands, but a modification that resulted in minimal reliance on working memory capacity or selective attention. For working memory trained animals (OLD/WM), training was based on a procedure used previously in our laboratory (Kolata et al. 2005) and described in detail in Light et al. (2010). In brief, mice were trained to asymptote on two distinct radial arm mazes, where the animals could collect food at the end of each of the eight arms. The mazes were located in the same room such that they shared common extra-maze visual cues (which are used by the animal to guide its search). After this initial training, the animals then performed concurrently on both mazes once a day for $12 \mathrm{~d}$ (constituting working memory training). During this training, mice alternated choices in the two mazes, and consequently, were required to maintain a memory of the choices in each maze, and segregate these memories despite the overlapping extra-maze visual cues. Thus, this training taxed both the maintenance of information as well as working memory capacity and selective attention. A second group of OLD animals (OLD/C; "control") received radial arm maze training that equated for sensory and motor experience but made minimal demands on working memory maintenance, capacity, or selective attention. For this training, animals were placed in each maze for an amount of time that was identical to the time spent by animals undergoing working memory training. However, the animals were placed in the mazes sequentially (as opposed to concurrently) and the food rewards were located within $2 \mathrm{~cm}$ of the entrance to each arm (as opposed to at the end of the arm) and were placed on the surface of the alley (as opposed to in a recessed cup). Thus, in this control training, animals could explore the maze and retrieve food, but were not reliant on the visual cues or the demands on working or selective attention that were imposed on animals that were receiving working memory training.

After $12 \mathrm{~d}$ of working memory or control training, all animals were assessed for acquisition of a learned response in five tasks (Lashley Maze, spatial water maze, passive avoidance, fear conditioning, and odor discrimination). Relative to animals that had not received working memory training, animals that received explicit working memory training exhibited an aggregate improvement in their performance across this battery of five tasks as reported in Light et al. (2010). Upon completion of this initial test, these animals continued to receive working memory or control training for approximately the next 15 mo. This chronic training was administered on three successive days at 3-wk intervals throughout this period, such that at 18 mo of age, animals had received an initial $12 \mathrm{~d}$ of this training followed by a total of 54 additional training sessions over the subsequent 14 mo.

When the above-described animals were $\sim 15$ mo of age, an additional group of $60 \mathrm{~d}$ old mice $(n=11)$ arrived in our laboratory. Upon arrival, these mice (young, control treatment; "YOUNG/C") were handled for 4 wk (as described previously). Subsequently, to equate the experience of these animals to their aged counterparts, they were administered the same learning test battery that was previously administered to the OLD animals. As this treatment was intended only to standardize the history of the three groups, the data from this training is not relevant to the present analysis and is not reported here. Upon completion 
of the learning battery (at $\sim 4$ mo of age) until the time of critical behavioral testing, mice in this group received equivalent food deprivation and food rewards (delivered in their home cages), as well as handling comparable to that administered to the $\mathrm{OLD} / \mathrm{C}$ group.

Tests of learning, reversal, and selective attention began when the aged animals (group OLD/WM and OLD/C) were $\sim 18$ mo of age and young animals (YOUNG/C) were $\sim 5$ mo of age. Two criteria were established for the inclusion and design of these behavioral tests. As all animals in this experiment had previously been tested in our standard battery of five learning tasks (Light et al.2010), behavioral tasks were designed to be as distinct as possible from those included in the original test battery. Second, we anticipated that aged animals might be particularly sensitive to tasks that demanded controlled processing or task switching (i.e., cognitive "flexibility") and, thus, tasks were included where such manipulations were easily implemented. Cognitive performance was assessed on the following four learning tasks, as well as a task designed to isolate selective attention.

1. Win-shift (reinforced alternation)/win-stay. This procedure was conducted in a T-maze with black Plexiglas walls and a grid floor (1-cm squares) constructed of white Plexiglas. A $22 \mathrm{~cm} \times$ $10 \mathrm{~cm}(1 \times \mathrm{w})$ start compartment led to a $10 \mathrm{~cm} \times 10 \mathrm{~cm}$ central (choice) compartment from which branched off two $42 \mathrm{~cm} \times$ $10 \mathrm{~cm}$ arms (perpendicular to the start compartment). One of these arms was lined with 1.25 -cm-wide vertical white stripes spaced $1.25 \mathrm{~cm}$ apart. The arm was lined with 1.25 -cm-wide horizontal white stripes spaced $1.25 \mathrm{~cm}$ apart. All walls were $24 \mathrm{~cm}$ high. The exit of the start compartment was segregated from the central compartment by a remotely operated clear Plexiglas guillotine door. The central compartment could be segregated from the two arms by independent remotely operated clear Plexiglas guillotine doors. At the end of each arm was a $3 \mathrm{~cm} \times 2 \mathrm{~cm}(w \times$ h) white plastic food cup.

Training was conducted over three consecutive days. On day 1 , animals were acclimated to the maze and allowed to make four forced choices. On the first exposure, the animal was held in the start box for $30 \mathrm{sec}$, after which it was allowed to traverse the maze; the door into the left arm was locked closed, and the right door was open. A food reinforcer (32 mg chocolate flavored puffed rice) was located in the food cup in the right arm. After consuming the food, the animal was returned to the start box for a 20 -sec intertrial interval (ITI). On the second exposure, this procedure was repeated, but the right door was locked and the left door open. After a 20-sec ITI, this sequence was repeated for two additional exposures. Through this sequence of four forced choices, the animals were acclimated to the maze.

On the subsequent day, training began. On all training trials, each choice door was fully open. On Trial 1, a reinforcer was available in both food cups and the animal could make a free choice. On the second trial, reinforcement was available in the arm not entered on the first trial. If an animal chose the correct arm, the location of the reinforcer alternated on the following trial. If an incorrect choice was made, the animal was allowed to correct its mistake and locate the food in the other arm. In either case, after the reinforcer was consumed, the animal was placed back in the start box to begin a 20-sec ITI. The animals' choices were recorded on each trial for the last 12 of the 13 trials. (As no error was possible on the first trial, data from this trial was not used.) The procedure was repeated on the next day, providing a total of 24 training trials.

On day 4, animals were subjected to a change in conditions from win-shift to win-stay. All animals' first choices were reinforced on day 4 . Thereafter, trials proceeded in the manner of days 2 and 3, except that the food reinforcer was consistently delivered on the same side as the animals' first choices. Thus, the animal was required to suppress its learned tendency to alternate choices.

2. Shuttle avoidance/passive avoidance. The shuttle box apparatus consisted of a rectangular box measuring $45.7 \mathrm{~cm} \times 19.7 \mathrm{~cm}$ $(l \times w)$. Aluminum walls measuring $18.7 \mathrm{~cm}$ high enclosed the sides of the apparatus, whereas the base of the apparatus was composed of a grid floor at which the bars were spaced $1.3 \mathrm{~cm}$ apart. A transparent piece of Plexiglas served as the lid of the apparatus. The apparatus was then further divided in half (lengthwise) by an aluminum partition with a $7.6 \times 7.6 \mathrm{~cm}$ doorway located directly in the center at the level of the base. This doorway was able to be blocked with a remotely operated clear Plexiglas door. To enhance discrimination between the two sides of the apparatus, the wall of one side (side A) had black vertical stripes measuring $1.9 \mathrm{~cm}$ in width and spaced $1.9 \mathrm{~cm}$ apart. A small light bulb (CM 1819) was mounted at the top of the wall opposite the doorway in side A. This light was normally off, and when operated, served as a conditioned stimulus (CS). The grid floors of the two sides (A and B) of the apparatus were wired to two independent shock generators, which generated a scrambled $0.6 \mathrm{~mA}$ foot shock.

The apparatus was located in a dark room lit indirectly by one $25 \mathrm{~W}$ incandescent light bulb (3 Lux at the grid floor). On the day prior to training, all animals were acclimated to the apparatus. Acclimation to the apparatus consisted of placing each animal in the apparatus for a period of $20 \mathrm{~min}$ with the center door opened in order to allow access to both sides of the apparatus.

On the subsequent day, training began. On the first training trial, the subject was placed in Side A for $60 \mathrm{sec}$ with door blocking access to side B. At the end of this $60 \mathrm{sec}$, the CS on side A was illuminated. Ten seconds after the onset of the CS, the floor of side A was electrified and the door was opened. This ensured that the subject would receive a shock before having the opportunity to escape to side $B$. The subject was then allowed free access to Side $B$, where upon entering, the shock was terminated (i.e., the animal could escape shock via an active shuttle response). All animals successfully escaped shock on this first trial. Ten seconds after the onset of the shock, both the CS and the shock were terminated, and the center door was lowered. The subject was then left in side B for $60 \mathrm{sec}$, after which it was moved back to side A to begin a 60-sec interval prior to the onset of the CS (i.e., Trial 2). On all trials subsequent to the first, the door was raised at the onset of the CS, allowing the animal to avoid shock by moving to Side B during the initial $10 \mathrm{sec}$ of the light CS, or to escape the shock by moving to side B after shock onset. The subjects received $5 \mathrm{~d}$ of training with five trials per day. Of interest was the number of training trials prior to stable initiation of successful avoidance responding during the initial $10 \mathrm{sec}$ of light presentation.

On the sixth day of training, each subject received two additional training trials (during which time all animals were exhibiting stable avoidance responding). Conditions were then reversed so as to require passivity to avoid shock. During five such reversal trials, the subject was left in side A for $1 \mathrm{~min}$, followed by the onset of the CS and the opening of the center door. During these trials, the floor of side B was electrified $10 \mathrm{sec}$ after the onset of the light and Side A remained safe. On these trials, a successful avoidance response required that the animals inhibit their previously learned shuttle response and instead avoid the shock passively by remaining on side A. After the termination of shock, the animals were left on side A for 2 min before the CS and shock were presented again.

3. Spatial water maze/reversed spatial water maze. This task requires the animals to locate a submerged platform in a pool of opaque water (from which they are motivated to escape). Absent distinct intramaze cues, animals' performances in this maze are highly dependent on their integration of spatial cues (Morris 1981). The latency and the path length to locate the platform decrease over successive trials, despite entering the pool from different locations on each trial. To differentiate this water maze from the water maze that all animals had previously undergone training in, the water color and surround was white (previously black), visual cues were constructed from black placards (previously patterns of lights), and the start locations and platform location was changed.

A round pool $(140 \mathrm{~cm}$ diameter, $56 \mathrm{~cm}$ deep) was filled to within $20 \mathrm{~cm}$ of the top with water that was clouded with a nontoxic, water soluble white paint. A hidden $14 \mathrm{~cm}$ diameter white platform was located in a fixed position $1 \mathrm{~cm}$ below the surface of the water. The pool was enclosed by a ceiling high white curtain on which five different black patterns (which served as spatial 
cues) were fixed at various positions. Illumination of the maze was 42 fear conditioning (FC) at the water's surface.

On the day prior to training, each animal was confined to the platform for $360 \mathrm{sec}$ by surrounding the platform with a clear Plexiglas cylinder. On the next two training days, the animals were started from one of three positions for each trial such that no two subsequent trials started from the same position. The animal was said to have successfully located the platform when it remained on the platform for $10 \mathrm{sec}$. After locating the platform or swimming for $90 \mathrm{sec}$, the animals were left or placed on the platform for $10 \mathrm{sec}$, after which they were removed for $10 \mathrm{~min}$ and placed in a holding box before the start of the next trial. Each animal completed 25 total trials (6/d for four consecutive days, and one additional trial on a fifth day). The latency and path to find the platform was recorded for each trial. On the fifth day (after the 25th training trial, the platform was moved to a new position in the quadrant opposite that which contained the platform on the previous 25 trials. Of interest was the animals' performances on the subsequent five trials (i.e., task reversal). These trials in which the platform was located in a new position proceeded in the same manner as the previous trials.

4. Step-down avoidance. In this assay, animals learn to suppress their exploratory tendency in order to avoid aversive stimuli. The animals are placed on a platform, and when they step down, are exposed to an aversive stimulus compound comprised of a bright light and loud oscillating tone (i.e., "siren"). To distinguish this task from the previous step-down avoidance task, a different chamber was constructed and a strong odorant was added to the environmental enclosure.

A chamber with a white grid floor $16 \times 12 \mathrm{~cm}(1 \times \mathrm{w})$ illuminated by a dim red light ( 4 FC) was used for both acclimation and testing. An enclosed "safe" platform $(10.0 \times 5.0 \times 5.0 \mathrm{~cm}, l \times w \times$ $h$ ) was constructed of black Plexiglas and was located $4 \mathrm{~cm}$ above the grid floor of a larger round arena $(24 \mathrm{~cm}$ diameter). This safe platform had one opening facing the grid floor, which allowed the animal to step down onto the floor. The exit from the platform was blocked remotely by a clear Plexiglas guillotine-style door. When the door was opened, the animal could step off of the safe platform, and upon making contact with the grid floor, would initiate the aversive stimuli. An odor ( $28 \mathrm{~g}$ Vick's VapoRub) was added to the chamber to further distinguish it from the chamber that had previously been used in the alternate version of passive avoidance.

Animals were placed on the platform with the door closed, confining them on the safe platform. After $5 \mathrm{~min}$, the door was opened and the latency of the animal to leave the platform and make contact with the floor was recorded. Upon making contact, the aversive compound stimulus was initiated for $4 \mathrm{sec}$, after which the exit door of the safe platform was once again closed. The animals were again confined on the platform for 5 min after which the door opened and their latency to step onto the grid floor was recorded for a second time. The ratio of the post-training step latency to pretraining step latency served as each animal's index of performance.

5. Selective attention. To assess differences in selective attention it was first necessary to train the animals to perform odor discrimination and visual discrimination in two related yet distinct contexts (Context ODOR and Context VISUAL, respectively).

Odor discrimination: Rodents are adept at using odor to guide their behavior. In this task, mice navigate through a square field using unique odors. The animals learn to choose the food cup that contains the target odor when given four choices. The food cup locations vary randomly, but the accessible food is always marked by the same target odor (in this case mint).

The odor discrimination chamber consisted of a black Plexiglas $60-\mathrm{cm}$-square field with $30-\mathrm{cm}$-high walls, which was located in a dimly lit room ( $\sim 10 \mathrm{Lux})$ with a high rate of air turnover. Each corner of the chamber was fitted with a $10-\mathrm{cm}$-wide wall (aligned $45^{\circ}$ to each side wall), which was also constructed of black Plexiglas and fit over the corners of the apparatus creating a $10-\mathrm{cm}$-wide flat surface in each corner. Affixed to the base of these interchangeable walls were food cups, which were affixed flush with the base of the wall. The flat surfaces of these corner panels could be backlit by a white LED, and each panel had a distinct pattern of holes forming one of four shapes: a circle, an X, a triangle, and two parallel horizontal lines. For odor discrimination training, these patterns were never illuminated.

The food cup affixed to the base of these interchangeable inserts was a square block of black Plexiglas measuring $7.5 \times$ $7.5 \times 1.5 \mathrm{~cm}$. In the center of the block was a food port measuring $1.5 \mathrm{~cm}$ in diameter and $1 \mathrm{~cm}$ in depth. This served as the reinforcer (30 $\mathrm{mg}$ portion of chocolate flavored puffed rice) location. This food port was covered during training and testing with a sliding piece of opaque Plexiglas measuring $42 \times 17 \times 1.5 \mathrm{~mm}$. This cover could pivot (in either direction) to expose the food port. All cups also contained inaccessible food in a chamber covered with screen cloth directly beneath the food port. This served as a nontarget odor cue to ensure that the scent of the reinforcer would not guide the animals' behavior toward the target cup. A cotton tipped laboratory swab that was loaded before each training trial with $25 \mu \mathrm{L}$ of lemon, mint, cinnamon, or almond flavored extract (McCormick PURE Flavor Extracts) extended vertically from the back corner of each cup. Mint was always the target odor and was associated with the accessible food reinforcer. (It is noted that animals were previously trained in a similar odor discrimination task in which mint served as the discriminative cue. However, we did not intend in the present task to assess the acquisition of this discrimination, but rather, to establish an odor cue that would later serve in our assessment of selective attention.)

Each animal received $1 \mathrm{~d}$ of acclimation and $2 \mathrm{~d}$ of training. On the acclimation day, the animals received four trials in order to train them to push the pivoting door in order to allow access to the food ports. During these acclimation trials the cotton tip laboratory swabs were placed in their relevant locations, but were not loaded with odor extract and only a single food port was baited with a reinforcer. On the first acclimation trial the animal was first placed into a perforated transparent Plexiglas cylinder $(11 \mathrm{~cm}$ in diameter and $12.7 \mathrm{~cm}$ in height) located in the center of the training chamber for $20 \mathrm{sec}$, after which the cylinder was removed to allow the animal to venture into the field. On this trial, the pivoting doors on the food cups covered only half of the food port. On the three successive trials ( 6 min ITI), the pivoting door was progressively closed so that by the fourth trial the food port was completely covered.

On the subsequent two training days, each animal received five training trials on each day. During this phase, the cotton tip laboratory swabs were loaded with $25 \mu \mathrm{L}$ of either mint, lemon, almond, or cinnamon extract. On these trials, an accessible food reinforcer was located under the pivoting door associated with the mint odor. (On only the first trial, an additional reinforcer was placed on the edge of the target cup.) At the beginning of each training trial the animals were once again placed in the clear Plexiglas cylinder located in the center of the apparatus for $20 \mathrm{sec}$. The animal was then released, and remained in the field until the food associated with the target odor was retrieved. At the end of each trial, the animal was returned to a holding chamber for a 6 min ITI, during which time the food cups were rearranged (i.e., located to different corners), but mint always remained as the target odor. For each trial, the number of errors to retrieve food was recorded. An error was constituted by the animal pushing a nontarget pivoting door enough to expose the food port, and or returning to a previously opened nontarget cup.

Visual discrimination: In this task, the animals learned to choose the target symbol among four possible choices to locate food. The visual discrimination box was made distinct from the odor discrimination box by the addition of white stripes on the walls measuring $1.9 \mathrm{~cm}$ in width and spaced $1.9 \mathrm{~cm}$ apart. The procedure proceeded exactly as specified for odor discrimination with the exception that the cotton laboratory swabs were not loaded with extract and that the visual cues (back lights) were illuminated. Here the mice were trained to associate the two horizontal lines with the location of the reinforcer. The total number of initial training trials was also increased from 10 to 15 trials (over $3 \mathrm{~d}$ ) as mice tend to learn about odor cues more quickly than visual cues (and animals had received no prior training on the visual discrimination). 
Following training on odor and visual discrimination, the animals were given additional overtraining trials upon which they received four odor discrimination trials and four visual discrimination trials separated by $4 \mathrm{~h}$ (on each day). This training phase continued until all animals reached an asymptotic level of performance (defined as a total of two errors or less over the final four training trials in any session). Following these overtraining trials the animals performed a complex discrimination task to assess selective attention. In these trials, the odor cues from odor discrimination training were introduced into the VISUAL discrimination box, and thus acted as salient task-relevant distracters. Animals received four such trials, and the total number of errors was once again recorded. Previously, using a similar task, the ability to effectively attend to target cues and to ignore task-relevant distracters has been reported to be a measure of selective attention and was found to be related to the animals' general cognitive performances (Kolata et al. 2007).

Navigation in a Lashley III maze. This maze consists of a start box, three interconnected alleys, and a goal box. Previous studies have shown that over successive trials, the latency and number of errors to find the goal decreases. When extra maze cues are minimized, the animals tend to use egocentric methods (e.g., fixed motor patterns) to locate the goal box. Here, it was our intention to assess learning in the Lashley maze. However, performance in this maze was clearly contaminated by prior training in a similar maze (i.e., animals exhibited near asymptotic performance after only a single training trial). Thus, acquisition data obtained on this task was determined to be potentially misleading and thus was not included in our analysis of cognitive performance. However, upon achieving stable levels of performance, the animals' running speeds could be estimated in this maze, and thus was used as an index of motor fitness.

A Lashley III maze scaled for use with mice (see Matzel et al. 2003) was constructed from black Plexiglas and located in a dimly lit room (10 Lux at the floor of the maze). A 3-cm-diameter white circle was located in the center of the goal box, and $45 \mathrm{mg}$ Bio-serv food pellets (dustless rodent grain) was placed in the cup to motivate the animals' behaviors.

On two successive days, food-deprived animals received a day of acclimation to the maze, followed by a single training day. Prior to the day of acclimation, all animals received three pellets of the reinforcer in their home cage. On the acclimation day, each mouse was confined in each of the first two alleys of the maze for $4 \mathrm{~min}$, and in the final alley (containing the goal box) for $6 \mathrm{~min}$. On this acclimation day, three pellets were placed in the goal box. At the end of each period, the animal was physically moved to the next alley. This acclimation exposure was intended to adapt the animals to the apparatus prior to actual training. On the subsequent training day, each animal was placed in the start box and allowed to freely navigate the maze, during which time their latency to locate the food was recorded. Upon locating and consuming the food pellet, the animal was returned to its home cage for a 25-min ITI, during which time the maze was cleaned. The animals completed five trials during the single training day. Running speed was determined based on each animal's performance during Trials 4 and 5 (see Results for a description of this analysis).

\footnotetext{
Analyses

To compare groups, one- or two-factor ANOVAs (where multiple test trials could serve as a repeated measure) were used to compare the groups' performance. General learning abilities were assessed with unrotated principal component analyses. For the principal component analysis, the animal's performance on learning tasks was assessed during acquisition. For this purpose, data for each animal on multitrial tasks were taken from the point in the acquisition curve that was intermediate between initial performance and terminal performance, i.e., in the middle of the acquisition phase. For this purpose, the average performance of two trials served as each animal's performance on multitrial tasks (for additional detail, see Matzel et al. 2003). In the tasks in which there was only one test trial (i.e., passive avoidance) we used training
}

parameters that we have previously found to result in subasymptotic responding during testing.

Across the course of testing, several animals in the aged groups became noticeably weak and/or died, and in several instances, apparatus malfunctions led to the elimination of one or more animals from a particular test. The number of animals that actually contributed to each task is provided in each section of the results, and the reported degrees of freedom varied accordingly.

To compare general cognitive performance across groups, animals were assigned factor scores derived from the principal component analysis. A factor score is analogous to an average $Z$-score for each animal computed from the $Z$-scores obtained for that animal on each task, with the $Z$-score for each task weighted for the degree to which that task contributed to the principal factor. The factor scores of young and aged animals were compared to assess differences in general learning abilities across the two ages.

\section{Acknowledgments}

This work was supported by grants from the National Institute of Aging (PHS AG022698 and AG029289) and the Busch Foundation to L.D.M.

\section{References}

Baddeley AD. 2003. Working memory: Looking back and looking forward. Nat Rev Neurosci 4: 829-839.

Baddeley AD, Logie RH. 1999. Working memory: The multiple component model. In Models of working memory: Mechanisms of active maintenance and executive control (ed. A Miyake, S Priti), Cambridge University Press, Cambridge.

Barnes CA. 1979. Memory deficits associated with senescence: A neurophysiological and behavioral study in the rat. J Comp Physiol Psychol 93: 74-104.

Barnes CA, McNaughton CL. 1985. An age comparison of the rates of acquisition and forgetting of spatial information in relation to long-term enhancement of hippocampal synapses. Behav Neurosci 99: $1040-1048$.

Cain DP, Saucier D, Hall J, Hargreaves EL, Boon F. 1996. Detailed behavioral analysis of water maze acquisition under APV or CNQX: Contribution of sensorimotor disturbances to drug-induced acquisition deficits. Behav Neurosci 110: 86-102.

Conway AR. 2010. Cognitive ability: Does working memory training enhance intelligence? Curr Biol 20: 362-364.

Conway AR, Engle RW. 1996. Individual differences in working memory capacity: More evidence for a general capacity theory. Memory 4: 577-590.

Conway AR, Kane MJ, Engle RW. 2003. Working memory capacity and its relation to general intelligence. Trends Cogn Sci 7: 522-547.

Durstewitz D, Seamans JK, Sejnowski TJ. 2000. Dopamine-mediated stabilization of delay-period activity in a network model of prefrontal cortex. J Neurophysiol 83: 1733-1750.

Engle RW, Tuholski SW, Laughlin W, Conway AR. 1999. Working memory, short-term memory, and general fluid intelligence: A latent variable approach. J Exp Psychol Gen 128: 309-331.

Gallagher M, Rapp PR. 1997. The use of animal models to study the effects of aging on cognition. Annu Rev Psychol 48: 339-370.

Gould TH, Feiro O. 2005. Age-related deficits in the retention of memories for cued fear conditioning are reversed by galantamine treatment. Behav Brain Res 165: 160-171.

Grossman H, Hale G, Light K, Kolata S, Matzel LD. 2007. Pharmacological modulation of stress reactivity dissociates its role in the determination of the relationship of exploration and general cognitive abilitiies. Behav Neurosci 121: 949-964.

Jaeggi SM, Buschkuehl M, Jonides J, Perrig WJ. 2008. Improving fluid intelligence with training on working memory. Proc Natl Acad Sci 105: 6829-6833.

Kolata S, Light K, Townsend DA, Hale G, Grossman H, Matzel LD. 2005. Variations in working memory capacity predict individual differences in general learning abilities among genetically diverse mice. Neurobio Learn Mem 84: 242-246.

Kolata S, Matzel LD, Light K. 2007. Selective attention is the primary determinant of the relationship between working memory and general learning abilities. Learn Mem 14: 22-28.

Kolata S, Light K, Matzel LD. 2008. Domain-specific and domain-general learning factors are expressed in genetically heterogeneous CD-1 mice. Intelligence 36: 619-629. 
Kolata S, Light K, Wass CD, Colas-Zelin D, Roy D, Matzel LD. 2010. A dopaminergic gene cluster in the prefrontal cortex predicts performance indicative of general intelligence in genetically heterogeneous mice. PLoS One 5: e14036.

Kramer AF, Bherer L, Colcombe SJ, Dong W, Greenough WT. 2004 Environmental influences on cognitive and brain plasticity during aging. J Gerontol A Biol Sci Med Sci 59: M940-M957.

Leal-Galicia P, Castaneda-Bueno M, Quiroz-Baez R, Arias C. 2008. Long-term exposure to environmental enrichment since youth prevents recognition memory decline and increases synaptic plasticity markers in aging. Neurobiol Learn Mem 90: 511-518.

Light K, Kolata S, Wass C, Denman-Brice A, Zagalsky R, Matzel LD. 2010. Working memory training promotes general cogntive abilities in genetically heterogeneous mice. Curr Biol 20: 777-782.

Lund PK, Hoyt EC, Bizon J, Smith DR, Haberman R, Helm K, Gallagher M. 2004. Transcriptional mechanisms of hippocampal aging. Exp Gerontol 39: $1613-1622$.

Markowska AL, Savonenko AV. 2002a. Protective effect of practice on cognition during aging: Implications for predicitive characteristics of performance and efficacy of practice. Neurobiol Learn Mem 78: 320.

Markowska AL, Savonenko AV. 2002b. Protective effect of practice on cognition during aging: Implications for predictive characteristics of performance and efficacy of practice. Neurobiol Learn Mem 78: 294-320.

Matzel LD, Kolata S. 2010. Selective attention, working memory, and animal intelligence. Neurosci Biobehav Rev 34: 23-30.

Matzel LD, Han YR, Grossman H, Karnik MS, Patel D, Scott N, Specht SM, Gandhi CC. 2003. Individual differences in the expression of a "general" learning ability in mice. J Neurosci 23: 6423-6433.

Matzel LD, Townsend DA, Grossman H, Han YR, Hale G, Zappulla M, Light K, Kolata S. 2006. Exploration in outbred mice covaries with general learning abilities irrespective of stress reactivity, emotionality, and physical attributes. Neurobio Learn Mem 86: 228-240.

Matzel LD, Grossman H, Light K, Townsend DA, Kolata S. 2008. Variations in age-related declines in general cogntiive abilities of Balb/C mice are associated with disparities in working memory span/capacity and body weight. Learn Mem 15: 733-746.

Matzel LD, Wass C, Kolata S, Light K, Colas DL. 2009. Age-related impairments of new memories reflect failures of learning, not retention. Learn Mem 16: 590-594.

Mizoguchi K, Shoji H, Tonaka Y, Maruyama W, Tabira T. 2009. Age-related spatial working memory impairment is caused by prefrontal cortical dopaminergic dysfunction in rats. Neuroscience 162: $1192-1201$.

Molden DC, Dweck CS. 2006. Finding "meaning" in psychology: A lay theories approach to self-regulation, social perception, and social development. Am Psychol 61: 192-203.

Morris RGM. 1981. Spatial localization does not require the presence of local cues. Learn Mot 12: 239-260.

Pesce V, Cormio A, Fracasso F, Lezza AM, Cantatore P, Gadaleta MN. 2005. Age-related changes of mitochondrial DNA content and mitochondrial genotypic and phenotypic alterations in rat hind-limb skeletal muscles. J Gerontol A Biol Sci Med Sci 60: 715-723.

Plomin R. 1999. Genetics and general cognitive ability. Nature $\mathbf{4 0 2}$

(Suppl): C25-C29.

Plomin R, Spinath FM. 2002. Genetics and general cognitive ability $(g)$. Trends Cogn Sci 6: 169-176.

Poldrack RA, Packard MG. 2003. Competition among multiple memory systems: Converging evidence from animal and human brain studies. Neuropsychologia 41: 245-251.

Riley MW, Riley JW Jr. 2000. Age integration: Conceptual and historical background. Gerontologist 40: 266-270.

Salthouse TA. 2005. Relations between cognitive abilities and measures of executive functioning. Neuropsychology 19: 532-545.

Salthouse TA, Ferrer-Caja E. 2003. What needs to be explained to account for age-related effects on multiple cognitive variables? Psychol Aging 18: $91-110$.

Salthouse TA, Atkinson TM, Berish DE. 2003. Executive function as a potential mediator of age-related cognitive decline in normal adults. J Exp Psychol Gen 18: 566-594.

Sawaguchi T, Goldman-Rakic PS. 1991. D1 dopamine receptors in prefrontal cortex: Involvement in working memory. Science 251: 947-950.

Span MM, Ridderinkhof KR, van der Molen MW. 2004. Age-related changes in the efficiency of cognitive processing across the life span. Acta Psychol (Amst) 117: 155-183.

Sternberg RJ. 1997. Intelligence and lifelong learning: What's new and how can we use it? Am Psychol 52: 1134-1139.

Sternberg RJ, Kaufman JC. 1998. Human abilities. Annu Rev Psychol 49: 479-502.

Stine-Morrow EAL. 2007. The Dumbledore hypothesis of cognitive aging. Curr Dir Psychol Sci 16: 295-299.

Stine-Morrow EA, Miller LM, Hertzog C. 2006. Aging and self-regulated language processing. Psychol Bull 132: 582-606.

Thurley K, Senn W, Luscher HR. 2008. Dopamine increases the gain of the input-output response of rat prefrontal pyramidal neurons. J Neurophysiol 99: 2985-2997.

Unsworth N, Engle RW. 2006. Simple and complex memory spans and their relation to fluid abilities: Evidence from list length effects. J Mem Lang 54: $68-80$.

Vicens P, Carrasco MC, Redolat R. 2003. Effects of early training and nicotine treatment on the performance of male NMRI mice in the water maze. Neural Plast 10: 303-317.

Yarkoni T, Braver TS, Gray JR, Green L. 2005. Prefrontal brain activity predicts temporally extended decision-making behavior. J Exp Anal Behav 84: $537-554$.

Young JW, Powell SB, Geyer MA, Jeste DV, Risbrough VB. 2010. The mouse attentional-set-shifting task: A method for assaying successful cognitive aging? Cogn Affect. Behav Neurosci 10: 243-251.

Received October 4, 2010; accepted in revised form March 13, 2011. 


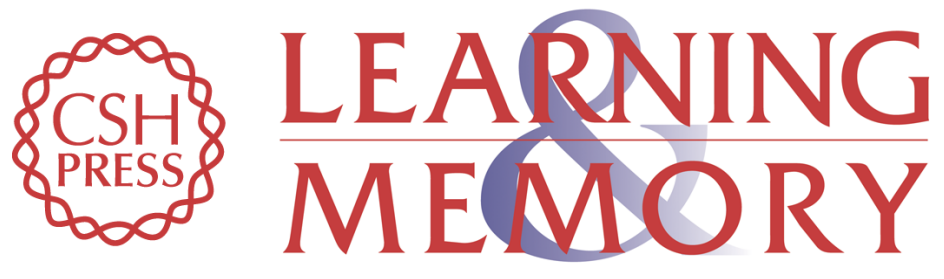

\section{Longitudinal attentional engagement rescues mice from age-related cognitive declines and cognitive inflexibility}

Louis D. Matzel, Kenneth R. Light, Christopher Wass, et al.

Learn. Mem. 2011, 18:

Access the most recent version at doi:10.1101/lm.2034711

References This article cites 50 articles, 6 of which can be accessed free at:

http://learnmem.cshlp.org/content/18/5/345.full.html\#ref-list-1

License

Email Alerting Receive free email alerts when new articles cite this article - sign up in the box at the Service top right corner of the article or click here. 